Available online on 15.09.2017 at http://jddtonline.info
Journal of Drug Delivery and Therapeutics
Open Access to Pharmaceutical and Medical Research
$\begin{gathered}\text { o 2011-17, publisher and licensee JDDT, This is an Open Access article which permits unrestricted } \\ \text { noncommercial use, provided the original work is properly cited }\end{gathered}$

Open $\odot$ Access

Review Article

\title{
FLIBANSERIN: A HAPPY ENDING SOLUTION TO HYPOACTIVE SEXUAL DESIRE DISORDER
}

\author{
Dick B. S. Brashier ${ }^{1}$, Prashant Mishra ${ }^{2}$, Neha Akhoon ${ }^{3}$, Htet Wai Moe ${ }^{3}$, Kedar G. Bandekar ${ }^{3}$ \\ ${ }^{1}$ Professor, Department of Pharmacology, Armed Forces Medical College, Pune- 411 040, Maharashtra, India \\ ${ }^{2}$ Classified Specialist (Pharmacology), Armed Forces Medical Services, New Delhi - 110001, India \\ ${ }^{3}$ Resident, Department of Pharmacology, Armed Forces Medical College, Pune- 411 040, Maharashtra, India
}

\section{ABSTRACT}

Hypoactive sexual desire disorder (HSDD) is a persistent or recurrent deficiency or absence of sexual desire. It can cause prominent distress and interpersonal difficulty of women. There have been drugs available to treat sexual disorders in men when there is no such drug for women. Nowadays, FDA approved Flibanserin to treat HSDD of premenopausal women. This drug Flibanserin has no novel mechanism of action but the possible mechanism of action is modulating serotonin and dopamine activity in brain parts as balance of these systems is significance for a normal sexual response.

Keywords: Hypoactive Sexual Desire Disorder, Premenopausal women, Flibanserin

Article Info: Received 25 July, 2017; Review Completed 09 August, 2017; Accepted 09 August, 2017; Available online 15 Sep, 2017

Cite this article as:

Brashier DBS, Mishra P, Akhoon N, Moe HW, Bandekar KG, Flibanserin: A happy ending solution to hypoactive sexual desire disorder, Journal of Drug Delivery and Therapeutics. 2017; 7(5):1-3

DOI: http://dx.doi.org/10.22270/jddt.v7i5.1504

*Address for Correspondence

Prashant Mishra, Classified Specialist (Pharmacology), Armed Forces Medical Services, New Delhi - 110001, INDIA. Email: drpmafmc@gmail.com

\section{INTRODUCTION}

In today era, where women are at par with men in every sphere of life, distress be it in relation to their professional life or personal life, it does prevail. Hypoactive sexual desire disorder (HSDD) which is characterized by persistent or recurrent deficiency or absence of sexual fantasies and desire for sexual activity is one such disorder which may arise due to personal distress ${ }^{1}$. This entity HSDD includes two further disorders, Female sexual arousal disorder (FSAD) and Female sexual interest arousal disorder (FSIAD) (FDA briefing document). In 2006, the women's international study of Health and sexuality (WISH) assessed the prevalence of HSDD and found out 24-36\% of women between 20 and 70 year of age had problems with low sexual desire ${ }^{2}$.Now the question which remains unanswered is, since there has been a line of drug coming upto treat such disorders in males, why much research work has not been found to treat the same problem in women. Complex physiology of female genital tract might come up as an answer, but does not suffice $^{3}$.

Finally a wonder drug with no novel mechanism of action, called Flibanserin has come up and has been approved by FDA in August $2015^{4}$.

\section{MECHANISM OF ACTION}

Flibanserin binds to 5 hydroxytryptamine $\left(5 \mathrm{HT}_{1 \mathrm{~A}}\right)$ receptor and acts as an agonist and it also acts as $5 \mathrm{HT}_{2 \mathrm{~A}}$ receptor antagonist. It also has weak partial agonist activity at Dopamine $\left(\mathrm{D}_{4}\right)$ receptor. The proposed mechanism of action refers to Kinsey dual control model of sexual response ${ }^{5}$. Various NT sex steroids are other hormones that have excitatory inhibitory on sexual response. Amongst NT, excitatory activity is driven by dopamine and noradrenaline while inhibitory activity is 
driven by serotonin ${ }^{6}$. The balance of these systems is significance for a normal sexual response. By modulating serotonin and dopamine activity in brain parts, Flibanserin improves the balance in regulation of sexual response ${ }^{7}$.

\section{PHARMACOKINETICS}

Flibanserin is rapidly absorbed with 90\% of dose reaching systemic circulation as drug itself or its metabolite. After oral administration, maximum plasma concentration $\left(\mathrm{C}_{\max }\right)$ is usually achieved in 45-60 minutes. Absolute bioavailability following oral dosing is $33 \%$. Food moderately affects the rate and extent of its absorption $^{8}$.

It is metabolized by CYP3A4and to minor extent by CYP2D6.It is excreted as conjugated metabolite via bile and kidney. Terminal $\mathrm{t}^{1 / 2}$ is approximately 12 hours ${ }^{9}$.

\section{DRUG INTERACTIONS}

Strong CYP3A4 and CYP2D6 inhibitors and inducers can alter the level of Flibanserin. Concomitant administration with alcohol increases the risk of somnolence, fatigue, orthostatic hypotension and syncope. Interaction with CYP3A4 inhibitor like fluconazole increases the risk of syncope and symptomatic hypotension $^{10}$.

\section{ADVERESE DRUG REACTIONS}

Most common reported adverse events included dizziness, nausea, and tiredness, disturbance in sleep. Concomitant intake of alcohol with Flibanserin results in severely low blood pressure ${ }^{11}$.

\section{CLINICAL TRIALS}

The drug has faced many issues in the past regarding its approval. In 2010, approval was denied pertaining to inadequate risk-benefit ratio. In June 2015, USFDA advisory committee recommended approval of the drug $^{12}$.In August 2015, FDA finally approved Flibanserin for the treatment of premenopausal women with low sexual desire that causes personnel distress or relationship difficulties. It was specially specified that it should not be used to treat low sexual desire caused by coexisting psychiatric or medical reasons. There are four main randomized controlled trials done to get approval of $\mathrm{FDA}^{13}$.

\section{DAISY STUDY}

Premenopausal women with Hypoactive Sexual Desire Disorder (HSDD) were randomized and treated with doses of Flibanserin $25 \mathrm{mg}$ and $50 \mathrm{mg}$ twice daily and $100 \mathrm{mg}$ once daily at night time or placebo for 24 weeks. The mean age of women is 35 years. Results showed that women receiving Flibanserin 50mg twice daily and $100 \mathrm{mg}$ once daily considered that their HSDD had improved with treatment ( $44 \%$ and $47 \%$ respectively). Only $30 \%$ of women receiving placebo receivers consider improvement. It can be found that in premenopausal women suffering from HSDD, Flibanserin $100 \mathrm{mg}$ once daily was tolerated and showed statistically significant improvement in sexual desire, sexual function and decrease of sexual distress compared to placebo $^{14}$.

\section{VIOLET STUDY}

Premenopausal women with HSDD were randomized and treated with Flibanserin 50mg, Flibanserin 100mg or placebo once daily dose at night time for 24 weeks. About $39 \%$ and $50 \%$ of women respectively receiving $50 \mathrm{mg}$ and $100 \mathrm{mg}$ Flibanserin considered improvement when only $30 \%$ of women receiving placebo considered improvement ${ }^{15}$.

\section{BEGONIA STUDY}

Premenopausal women (mean age: 36.6 years) were randomized and given treatment with Flibanserin 100mg once daily dose at night time or placebo for duration of 24 weeks. The $38 \%$ of women treated with Flibanserin considered marked improvement and also showed significant reductions in distress associated with sexual dysfunction. Only $28 \%$ of placebo group considered improvement ${ }^{16}$.

\section{SNOWDROP STUDY}

Postmenopausal women with HSDD were treated with Flibanserin $100 \mathrm{mg}$ once daily at night time or placebo for 24 weeks. The $37 \%$ of women treated with Flibanserin $100 \mathrm{mg}$ and $28 \%$ of women receiving placebo considered the improvement respectively ${ }^{17}$.

\section{DRUG ABUSE AND DEPENDECNCE}

There is no increase in drug-seeking behavior, misuse and abuse once marketed. The only possible abuse is that men can force their partner to take this medicine to increase their desire ${ }^{18}$.

\section{PRESENT STATUS}

Flibanserin is available as $100 \mathrm{mg}$ tablet. The recommended dose is $100 \mathrm{mg}$ taken one time a day at bedtime. It can be taken only at bedtime as it can increase the risk of low blood pressure, fainting attack, accidental injury and sleepiness ${ }^{19}$.

\section{CONCLUSION}

Hypoactive Sexual Desire Disorder (HSDD) is a woman's ongoing lack of sexual interest or desire that causes prominent distress and interpersonal difficulty. Flibanserin is the first and only approved drug of FDA to treat Hypoactive Sexual Desire Disorder (HSDD) in premenopausal women ${ }^{20}$. 


\section{REFERENCES}

1. Clayton AH, Goldfischer E, Goldstein I,DeRogatis L, Nappi R, Lewis-D'Agostino DJ, Kimura T, Hebert A, Pyke R.Validity of the decreased sexual desire screener for diagnosinghypoactive sexual desire disorder. J Sex Marital Ther 2013; 39:132-43.

2. Clayton AH, DeRogatis LR, Rosen RC, Pyke R. Intended or unintended consequences? The likely implications of raising the bar for sexual dysfunction diagnosis in the proposed DSM-V revisions: 1 . For women with incomplete loss of desire or sexual receptivity. J Sex Med 2012; 9:2027-39.

3. Basson R, Driscoll M, Correia S. Flibanserin for Low Sexual Desire in Women: A Molecule from Bench to Bed? EBioMedicine. 2015; 2(8):772-773.

4. Gohil K. Pharmaceutical Approval Update. Pharmacy and Therapeutics. 2015; 40(10):649-689.

5. Uphouse L. Pharmacology of serotonin and female sexual behavior. Pharmacology, biochemistry, and behavior. 2014; $0: 31-42$.

6. Zakiniaeiz Y, Cosgrove KP, Potenza MN, Mazure CM. Balance of the Sexes: Addressing Sex Differences in Preclinical Research. The Yale Journal of Biology and Medicine. 2016; 89(2):255-259.

7. Chilmonczyk Z, Bojarski AJ, Pilc A, Sylte I. Functional Selectivity and Antidepressant Activity of Serotonin 1A Receptor Ligands. Hashimoto K, ed. International Journal of Molecular Sciences. 2015; 16(8):18474-18506.

8. Sang JH, Kim T-H, Kim SA. Flibanserin for Treating Hypoactive Sexual Desire Disorder. Journal of Menopausal Medicine. 2016; 22(1):9-13.

9. Stahl SM. Mechanism of action of flibanserin, a multifunctional serotonin agonist and antagonist (MSAA), in hypoactive sexual desire disorder. CNS Spectr 2015; 20:1-6.

10. Nappi RE. Why are there no FDA-approved treatments for female sexual dysfunction? Expert Opin Pharmacother $2015 ; 16: 1735-8$.
11. Levine SB. Flibanserin. BMJ 2015; 350:h3097.

12. UphouseL. Pharmacology of serotonin and female sexual behavior. Pharmacology, biochemistry, and behavior. 2014; 0:31-42.

13. ZhenliGao, Diandong Yang, Luxin Yu, MD, Yuanshan Cui. Efficacy and Safety of Flibanserin in Women with Hypoactive Sexual Desire Disorder: A Systematic Review and Meta-Analysis.J Sex Med 2015; 12:2095-2104.

14. Thorp J, Simon J, Dattani D, Taylor L, Kimura T, Garcia MJ, Lesko L, Pyke R. Treatment of hypoactive sexual desire disorder in premenopausal women: Efficacy of flibanserin in the DAISY study. J Sex Med 2012; 9:793-804.

15. Derogatis LR, Komer L, Katz M, Moreau M, Kimura T, Garcia MJ, Wunderlich G, Pyke R. Treatment of hypoactive sexual desire disorder in premenopausal women: Efficacy of flibanserin in the VIOLET Study. J Sex Med 2012; 9:1074-85.

16. Katz M, DeRogatis LR, Ackerman R, Hedges P, Lesko L, Garcia MJ, Sand M. Efficacy of flibanserin in women with hypoactive sexual desire disorder: Results from the BEGONIA trial. J Sex Med 2013; 10:1807-15.

17. Simon JA, Kingsberg SA, Shumel B, Hanes V, Garcia MJ, Sand M. Efficacy and safety of flibanserin in postmenopausal women with hypoactive sexual desire disorder: Results of the SNOWDROP trial. Menopause 2014; 21:633-40.

18. Gohil K. Pharmaceutical Approval Update. Pharmacy and Therapeutics. 015; 40(10):649-689.

19. Addyi Approval History. Available at: https://www.drugs.com/history/addyi.htmlAccessed on 18.08.2016.

20. FDA Approval of Flibanserin - Treating Hypoactive Sexual Desire Disorder. Available at: http://www.nejm.org/doi/full/10.1056/NEJMp1513686\#t=art icle Accessed on 18.08.2016. 